\title{
An atlas of southern African pollen types and their climatic affinities
}

\author{
Manuel Chevalier ${ }^{1}$ \\ Institute of Earth Surface Dynamics, Geopolis, University of Lausanne, \\ Switzerland
}

Brian M. Chase $\mathrm{C}^{2}$

Institut des Sciences de l'Evolution-Montpellier (ISEM), University of

Montpellier, Centre National de la Recherche Scientifique (CNRS), EPHE, IRD, Montpellier, France.

Lynne J. Quick

African Centre for Coastal Palaeoscience, Nelson Mandela University, Port Elizabeth, South Africa

\section{Louis Scott}

Department of Plant Sciences, University of the Free State, Bloemfontein, South Africa

\begin{abstract}
Interpretations of fossil pollen data are often limited to broad, qualitative assessments of past climatic and environmental conditions (e.g. colder $v s$. warmer, wetter $v s$. drier, open $v s$. closed landscape). These assessments can be particularly imprecise in regions such as southern Africa, where botanical biodiversity is high, and there exists an associated uncertainty regarding the climatic/environmental sensitivities of the plants contributing to a given pollen type. This atlas addresses this limitation by characterising the climate sensitivities of the 140 pollen morphotypes most often recorded in Late Quaternary palaeoecology studies in southern Africa, relying on their parent plant distributions as one of the basic factors that determine their presence. The atlas is designed as a suite of graphical diagnostic tools and photographs together with analyses of the modern geographical distribution of more than 22,000 plant species to identify their primary climatic sensitivities across southern Africa. Together, the elements included span the complete workflow from pollen identification through interpretation and climate reconstruction. The atlas can be accessed from https://doi.org/10.5281/zenodo.4013452.
\end{abstract}

\footnotetext{
${ }^{1}$ Other affiliation: Institute of Geosciences, Sect. Meteorology, Rheinische Friedrich-Wilhelms-Universität Bonn, Bonn, Germany

${ }^{2}$ Other affiliation: Department of Environmental and Geographical Science, University of Cape Town, Rondebosch, South Africa
} 


\subsection{INTRODUCTION}

Fossil pollen records have been a key source of palaeoenvironmental information in southern Africa for decades (Coetzee 1967; Finch and Hill 2008; Lim et al. 2016; Neumann et al. 2010, 2011, 2014; Quick et al. 2016, 2018; Scott and Nyakale 2002; Scott and Woodborne 2007; Scott et al. 2012; Scott 1982, 1989, 1999; Valsecchi et al. 2013; van Zinderen Bakker and Coetzee 1988; van Zinderen Bakker 1957, 1982; e.g. Bousman et al. 1988). While it is generally understood that a range of edaphic and ecological factors may influence plant distributions and vegetation composition, it is common for interpretations of pollen records to focus on plant climatic affinities and the reconstruction of past climate change. However, plant-climate relationships are often complex, and interpretive frameworks based on individuals' assessments of climate conditions where a given taxon occurs often lack the comprehensive consideration required to establish the relative influence of specific climatic parameters. Further, as pollen morphotypes (hereafter referred to as pollen types) commonly comprise more than one single species, defining the climatic affinity of a pollen type quickly becomes exceedingly complicated. These issues are amplified in regions with high botanical diversity, such as southern Africa, where tens or even hundreds of species, sometimes with distinct climate requirements, are subsumed within undifferentiated pollen types that can cover wide ranges of ecological and climatic conditions. In practice, robust statistical estimates of the specific climate affinities (both in terms of their tolerances and associated optima) are missing for the vast majority of the commonly observed pollen types, which often limits interpretations of fossil pollen data to relatively coarse-scale qualitative - and often subjective - climatological and/or environmental considerations.

The development of the CREST (Climate REconstruction SofTware) method (Chevalier et al. 2014) has enabled the production of the first quantitative climate reconstructions using fossil pollen records in southern Africa. CREST is based on the definition of independent, taxon-specific probability density functions (pdfs) to model a probabilistic relationship between pollen and climate from an ensemble of modern plant geolocalised occurrence data (hereafter 'plant distributions'). While more commonly used reconstruction techniques - such as modern analogues (Overpeck 1985; e.g. Imbrie and Kipp 1971), or regression techniques (ter Braak and Looman 1986; e.g. ter Braak and Juggins 1993) - rely on large collections of modern pollen samples to estimate pollen-climate relationships, such samples cannot be obtained for every environment or vegetation type of southern Africa. This limitation has strongly restricted their use in the region (Chevalier et al. 2014). In contrast, CREST uses widely-available plant distributions as calibration data (Chevalier 2019), and has proven efficient at reconstructing the different climates and vegetation types of the region (Chase et al. 2015a, 2015b, 2017; Chevalier and Chase 2016; Chevalier et al. 2021a; Cordova et al. 2017; Lim et al. 2016). As with all reconstruction techniques, the most reliable results are usually obtained when the method is run using a subset of taxa that are strongly influenced by the climatic parameter being reconstructed (Juggins et al. 2015; Kühl et al. 2002; Truc et al. 2013). The selection of the subset of taxa for climate reconstructions can be, however, subjective, as these selections are often based on the field experience of individuals, which could lead to inaccuracies because either the full distribution of the taxon is not considered, or the taxon is misattributed to certain conditions.

In this paper and accompanying supplementary atlas (Chevalier et al. 2021b), we present a series of diagnostic tools and results based on statistical analyses of the modern distributions of the parent plants of 140 southern African pollen types most commonly found in fossil records in relation to five key climate variables that capture the main climate gradients of the regions. This paper discusses how these diagnostics tools can be used to improve both palaeoecological interpretations and palaeoclimatological analyses derived from fossil pollen records. This atlas allows for a more accurate determination of the absolute and relative climate sensitivities of plants that produced the pollen types considered, which will facilitate both improved qualitative interpretations and the use of quantitative reconstruction methods. The user should be cognisant 
of the fact that this atlas does not account for the effect of non-climatic parameters, such as soil characteristics or fire, which may also be important determinants of some plant distributions. As such, the plant-climate relationships described in this atlas should always be balanced with considerations of the ecology of the studied taxa.

\subsection{MATERIAL AND METHODS}

\subsubsection{Botanical Data}

To estimate the climate responses of the different taxa, we used botanical data from the Global Biodiversity Information Facility (GBIF) database (GBIF.org 2020a, 2020b, 2020c, 2020d, 2020e, 2020f, 2020g, 2020h, 2020f; 'GBIF: Global Biodiversity Information Facility,' 2018) using the curated dataset of Chevalier $(2019,2018)$. These data are available as 'presence-only' observations (i.e. the absences and abundances are not documented) and their spatial resolution are homogenised at $0.25^{\circ} \times 0.25^{\circ}$ grid square $\left(c .900 \mathrm{~km}^{2}\right.$ at the latitudes of southern Africa). To build the atlas, we have used a total of 475,712 occurrence records, which correspond to 22,496 species grouped in 140 pollen types. The number of observed species in each grid cell varies between 1 and 2815, with a median of 17 species and a mean of 81 species.

The distribution of these data is spatially heterogenous (Figure $1 \mathrm{~A}$ ), with $>75 \%$ of the records being concentrated in South Africa and its biodiversity hotspot (Rutherford et al. 2012; the Greater Cape Floristic Region; Myers et al. 2000). This sampling bias is also visible along

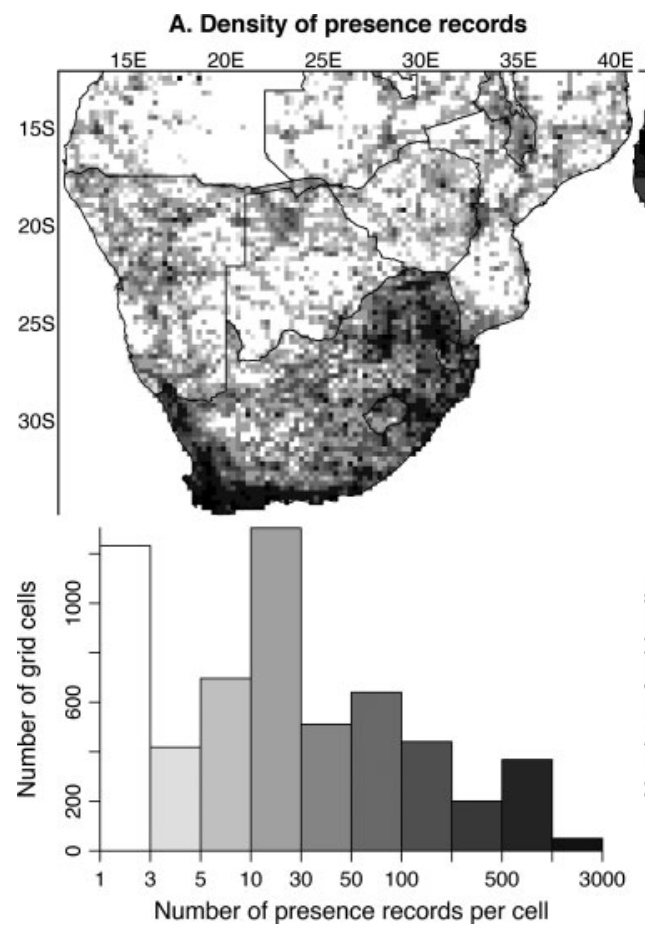

\section{B. Temperature of the Wettest Quarter}
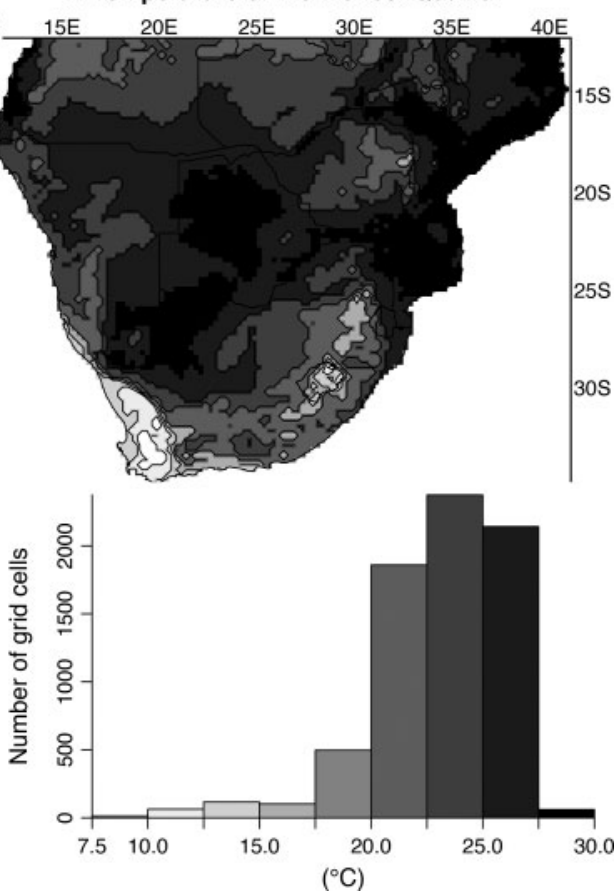

Figure 1. (A) Distribution of presence records (plant unique observations) across the study area (note the log scale for the colour gradient). This figure highlights the two biodiversity hotspots of the region, as well as a different degree of sampling across the study area. (B) TWetQ across the study area. 
the South African border. The other countries composing our study area are less well represented, especially eastern Angola and western Zambia. However, the modern climate and vegetation gradients are less steep in those regions than they are in the southern part of the study area, where orography increases spatial variability. As such, it may be considered that the lower sampling density is sufficient to capture the full range of climate response of the studied taxa in these regions. It should also be remembered that some of the botanical data has been obtained from environments that have been influenced by human activity. While this could be considered as a factor that might undermine the natural plant-climate relationships that form the basis for this work, studies have shown that the plant-climate relationship remains robust as long as the full range of conditions experienced by the plant are sampled (Chevalier et al. 2014), and any anthropogenic bias is minimal.

Finally, it is important to note that a strict classification of plant species into pollen types is often not possible and our classification may contain related errors and/or regional biases. As plant and pollen taxonomies are being regularly improved, our classification is a compromise between the most recent changes and decades of palynological expertise. In general, the classification scheme adopted here maintains older names to remain consistent with published pollen records. For example, we use 'Acacia-type', even as African Acacia are now Vachellia and Senegalia. The full list of species composing each pollen type in southern Africa is available at the end of the atlas (Chevalier et al. 2021b).

\subsubsection{Climate Data}

We used a subset of the Worldclim 2 climatology (Fick and Hijmans 2017) to generate the atlas. These climate data represent the mean climate between the years 1970 and 2000 and are available at several spatial resolutions. Here, we used the $5 \operatorname{arcmin}$ resolution climatologies $\left(c .0 .083^{\circ}\right)$ and upscaled them to the resolution of the botanical data (Chevalier 2019). Among the wide range of annual and seasonal bioclimatic variables that are generally considered important elements in studying the eco-physiological tolerance of plants species (Guisan and Thuiller 2005; e.g. Elith et al. 2006), we identified five key variables based on the following criteria: (i) they have a direct impact on plants life cycle (i.e. variables also called 'direct gradients' by Guisan and Zimmermann 2000), which is critical to estimate reliable plant-climate relationships, (ii) they are important descriptors of southern African climates and also (iii) they are largely uncorrelated across the study area (Table 1). Together, the selected five variables reflect many important aspects of the regional climatic drivers and are expected to be major determinants of plant distributions. By extension, it is expected that these variables can be reconstructed from regional fossil pollen records (Chevalier et al. 2020). The five variables we selected are:

(1) the mean temperature of the wettest quarter (TWetQ $\left[{ }^{\circ} \mathrm{C}\right]$, Figure 1B), which we use here as a proxy for the temperature of the growing season,

(2) the minimum temperature of the coldest month (TColdM $\left[{ }^{\circ} \mathrm{C}\right]$, Figure $2 \mathrm{~A}$ ) used here as a proxy for cold/frost tolerance,

(3) the accumulated precipitation of the warmest Quarters (PWarmQ [mm], Figure 2B),

(4) the accumulated precipitation of the coldest Quarters (PColdQ [mm], Figure 2C), and

(5) an Aridity Index (Aridity [unitless], Figure 2D) also derived from Worldclim 2 as a ratio between potential evapotranspiration (PET) and mean annual precipitation (Trabucco and Zomer 2019; MAP; Trabucco et al. 2008). With this definition, environmental changes along the Aridity gradient are not linear and environmental changes are larger across specific sections of the gradient. We, therefore, calculated the square-root of the Aridity values to 'stretch' the spatially-abundant arid to sub-humid section of the southern African Aridity 
Table 1. Spearman's correlation indices between the five selected climate descriptors. None of these correlations are significant at the 5\% level (without even correcting for multiple testing), highlighting the statistical independence of our climate descriptors across the entire study area.

\begin{tabular}{lccccc}
\hline & TWetQ & TColdM & PWarmQ & PColdQ & Aridity \\
\hline TWetQ & 1 & & & & \\
TColdM & -0.017 & 1 & 1 & & \\
PWarmQ & 0.004 & 0.014 & -0.006 & 1 & \\
PColdQ & -0.006 & 0.019 & 0.003 & -0.014 & 1 \\
Aridity & -0.002 & 0.011 & & & \\
\hline
\end{tabular}

gradient and 'shrink' the most humid sections to increase the sensitivity of our modelling approach (e.g. Turner et al. 2020).

\subsubsection{Pollen Photographs}

Most of the pollen images are taken from the reference collection of African pollen types that was created by E.M. van Zinderen Bakker and co-workers at the University of the Free State, for a series entitled South African Pollen Grains and Spores, between 1953 and 1970 after extensive collection from several herbaria in Africa and Europe (Coetzee 1955; van Zinderen Bakker and Coetzee 1959; van Zinderen Bakker et al. 1970; van Zinderen Bakker 1953, 1956). Other photos were taken from the University of Cape Town reference collections (created by Jean Sugden and Sue De Villiers) and the African Pollen Database.

\subsection{THE CREST METHOD}

CREST uses probability density functions (pdfs) to estimate univariate statistical relationships between pollen and climate variables (Chevalier et al. 2014; Chevalier 2019). The process is based on two steps (Figure 3). First, each plant species is considered independently to calculate its pdfs, which can be interpreted as the realised niche of the species (Kearney 2006). Species pdfs are fully defined by two parameters, a mean and a standard deviation, which can be interpreted as the plant's climate preference (the optimum position on the climate gradient) and tolerance (the shape/width of the niche), respectively. To ensure a robust estimation of these two parameters, only species with a minimum of 20 grid cells in their distributions are considered in this study. Climate values are obtained by associating their occurrence data with climate gradients of interest, each being weighted according to the inverse of their abundance in the climate space (i.e. the histograms on Figures 1 and 2; Bray et al. 2006; Kühl et al. 2002). Following the recommendations of Chevalier et al. (2014), we imposed a symmetrical normal distribution for the species pdfs of TWetQ and TColdM and a right-skewed log-normal distribution (negative values have a probability of 0 ) for the species pdfs of PWarmQ, PColdQ and Aridity.

Finally, all the species pdfs of the species composing a pollen type are given a weight that corresponds to the square-root of the number of grid cells composing their distribution (i.e. species with larger distributions get a higher weight). A weighted average of their pdfs is then performed to integrate the full climatic spectrum occupied by the different species into one single response curve and meet the taxonomic resolution of the pollen type. No additional constraints are imposed to the shape of the resulting curve, which can be asymmetric (Figure 3 ) or multimodal 
A. Minimum temperature of the coldest month
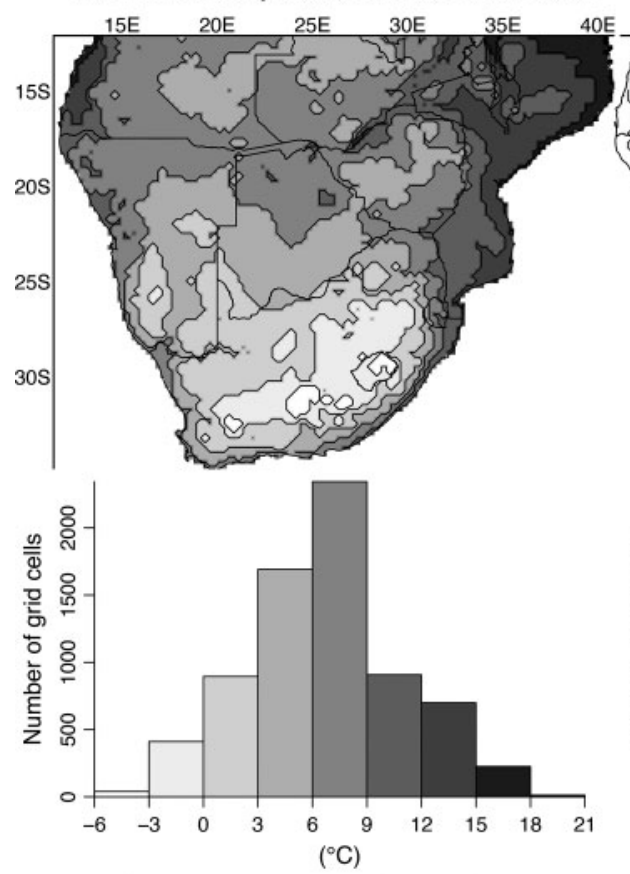

C. Precipitation of the Coldest Quarter
B. Precipitation of the Warmest Quarter
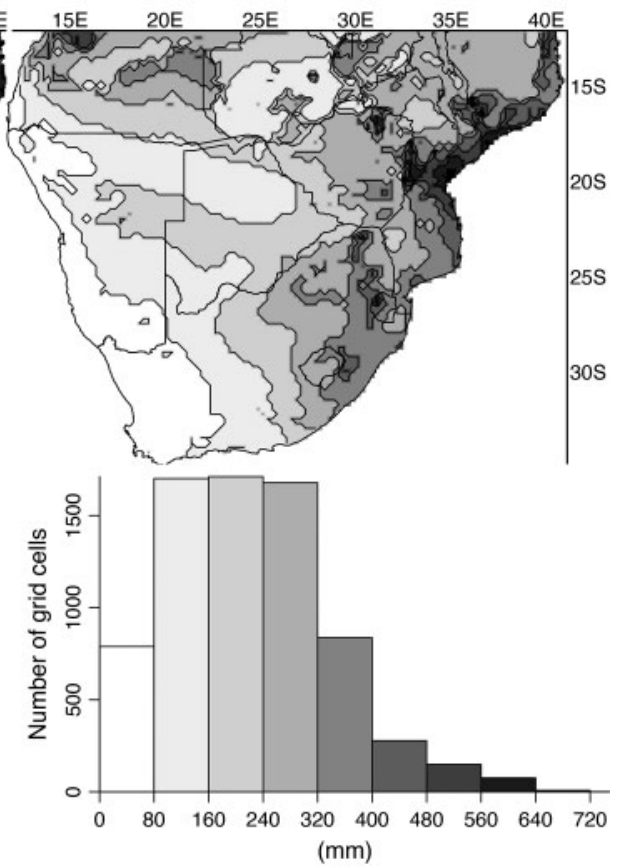

D. Aridity Index
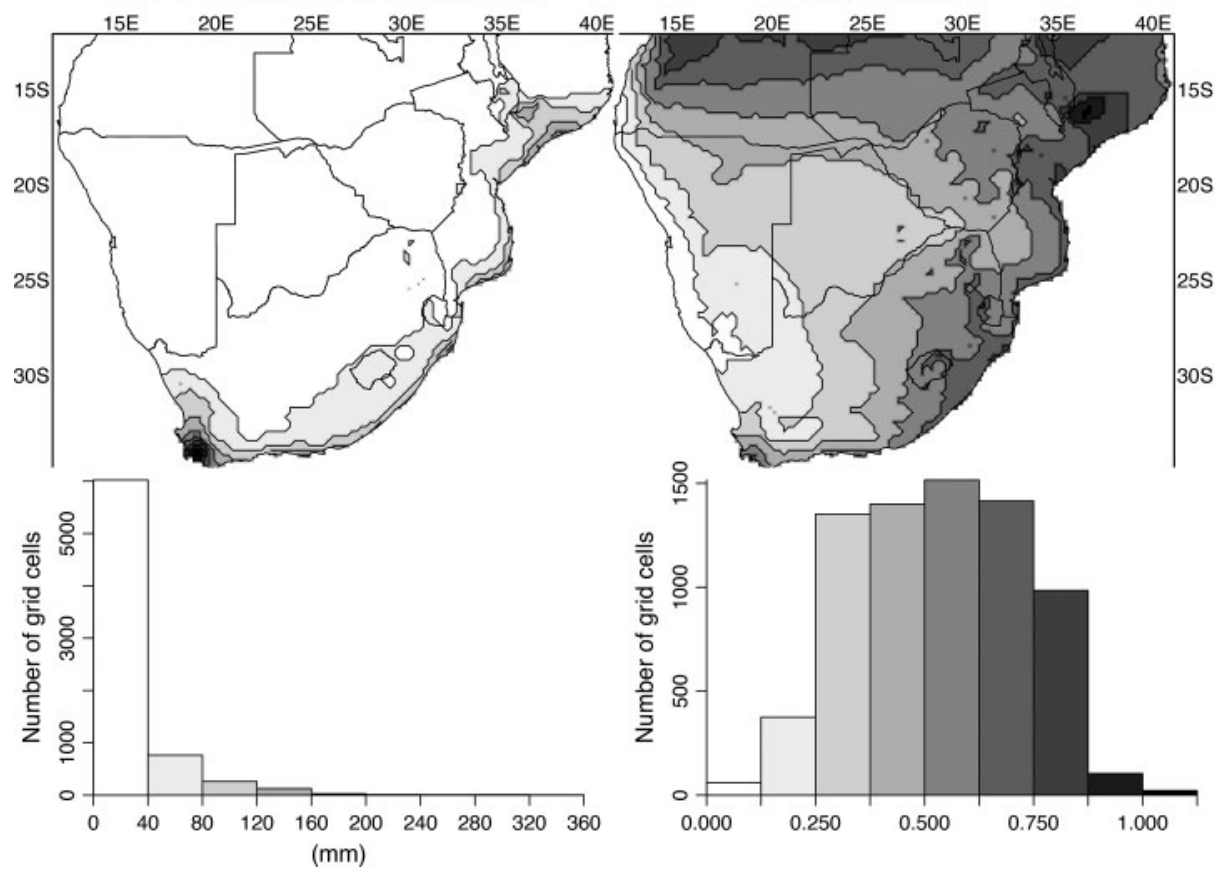

Figure 2. Distribution of (A) TColdM, (B) PColdQ, (C) PWarmQ and (D) Aridity Index values (low to high values for arid to humid conditions) across the study area. 
A. Environmental gradient

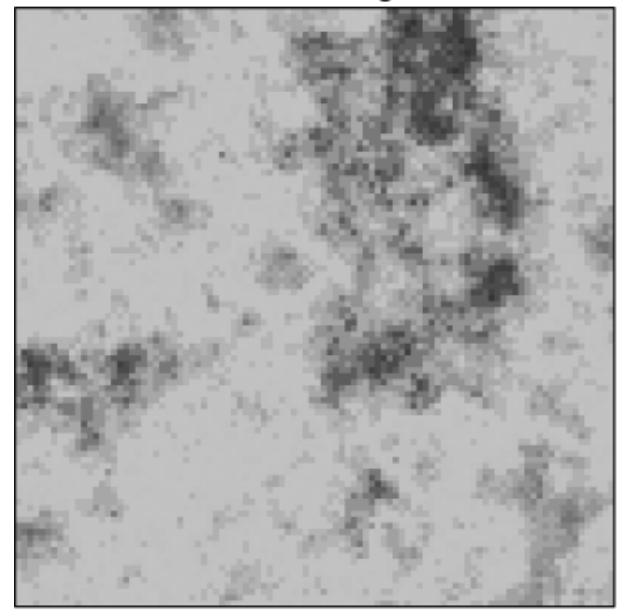

$-$

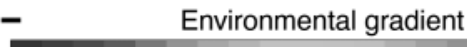

\section{B. Species distributions}
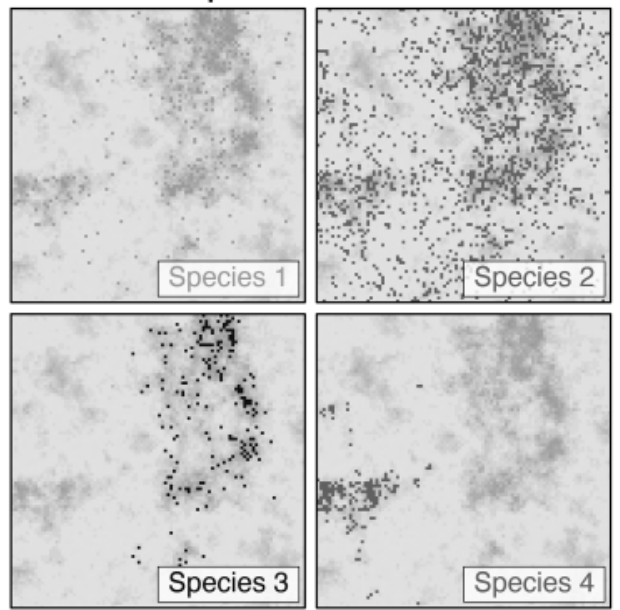

$+$

D. Climate response (pollen pdf)

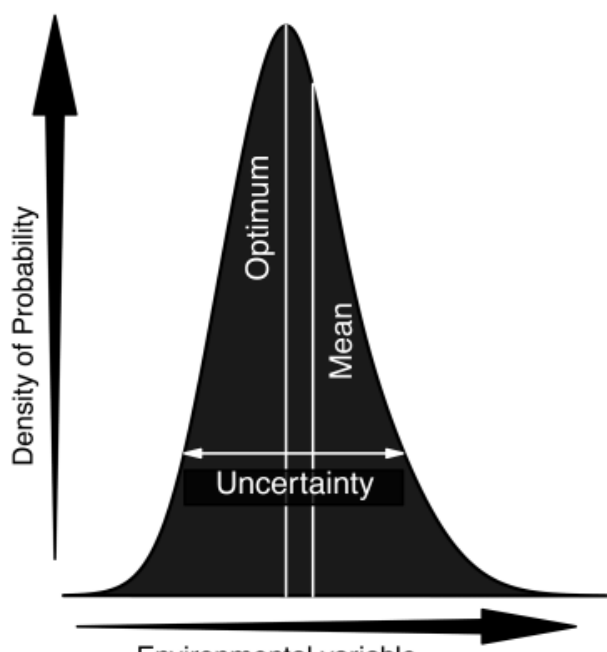

Environmental variable

Figure 3. Conceptual representation of the fitting of probability density functions (pdfs) using randomly generated data. (A) Modern distribution of the environmental variable of interest. (B) Modern distribution of four species producing undifferentiated pollen grains in the environment. (C) Four curves representing four pdfs of the species represented in B. Inset histogram represents distribution of modern environment (white) that is occupied by at least one of the four species of interest (black), highlighting the preference for lower values. (D) Representation of statistics

(optimum, mean, and width/uncertainty) that can be measured from each $p d f$ to infer climate preferences and tolerances.

(i.e. exhibiting two or more different climate preferences) if necessary. In this study, the pdfs are only used to characterise the climatic sensitivities of various pollen types. For more details on how to use them to reconstruct climate, we refer to the original publications (Chevalier et al. 2014; Chevalier 2019). 


\subsection{IDENTIFICATION OF STRONGEST CLIMATIC DETERMINANTS}

This section presents how the different diagrams and pdfs curves generated for each taxon in the atlas (a combination of Figures 3 to 6) can be used to evidence specific or relative climate sensitivities. The first two examples (Poaceae - Figure 4 - and Menispermaceae - Figure 5) provide simple diagnostic criteria to identify the taxa that cannot be used as clear indicators of climate in (semi-)quantitative frameworks, while the last one (Artemisia - Figure 6) uses the graphical diagnostics tools to identify the most influential climatic parameters of the plant distribution. However, it is important to clearly differentiate 'non-informative taxa' from 'taxa from which quantitative information cannot be extracted' and to stress that excluding pollen types, such as Poaceae, from quantitative interpretations does not mean they do not convey any valuable information. Integrated in an ecological/qualitative, rather than in a statistical/quantitative approach, they can provide critical indications of palaeoenvironmental changes, as shown by the sensitive, but biome-dependent, Asteraceae:Poaceae pollen ratio at Pella, South Africa (Lim et al. 2016) and as previously suggested in central South Africa (Coetzee 1967; Cooremans 1989). Non-informative taxa can also be used as a semi-independent, but complementary source of information to support climate reconstructions.
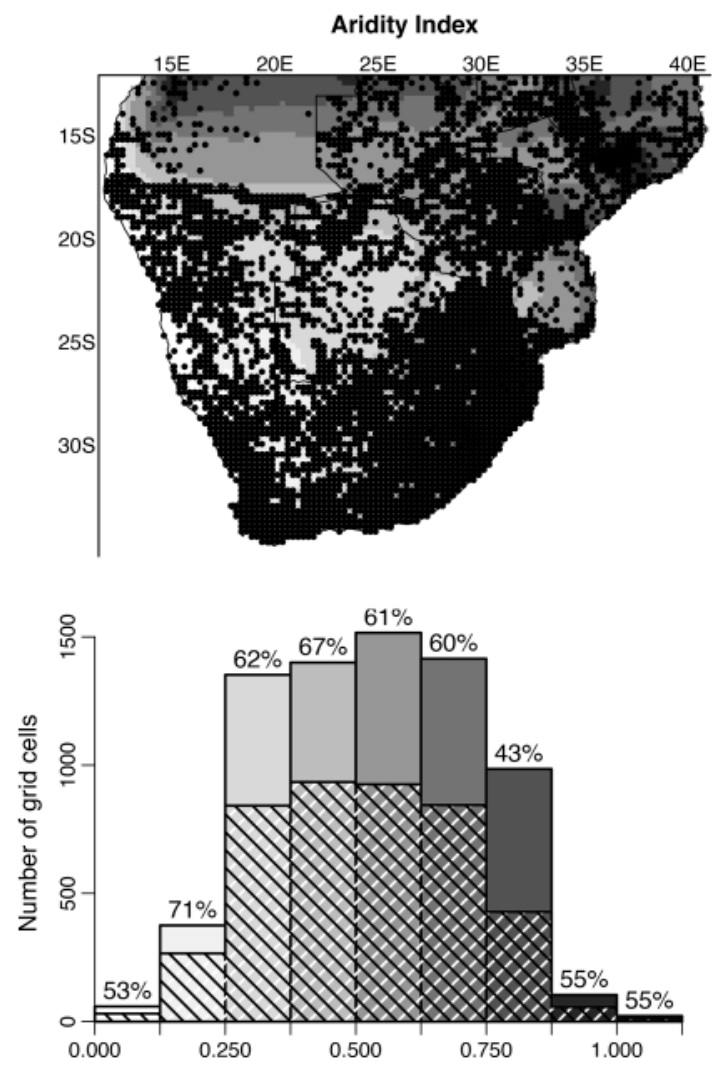

Figure 4. Distribution of Poaceae (black dots) compared to Aridity Index values across the study area; refer to Figure 2D to see the masked parts (top panel). Histogram that represents the proportion of the aridity space (grey scale) that is occupied (hatched) by at least one Poaceae species (bottom panel). 
A. Distribution of Menispermaceae in southern Africa

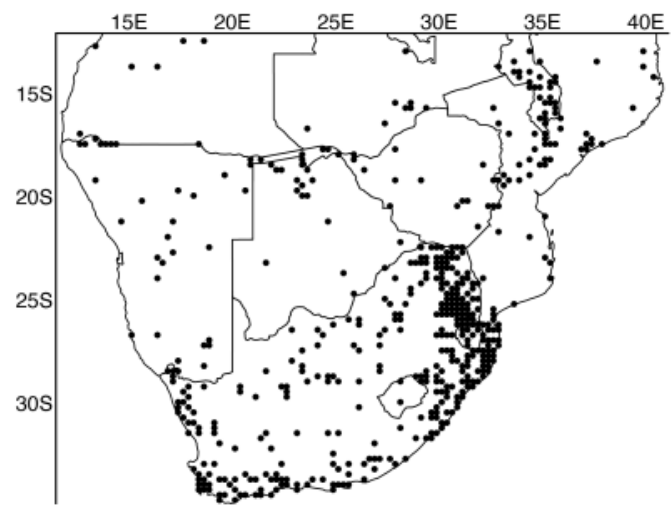

B. Distribution of Menispermaceae in the climate space of southern Africa
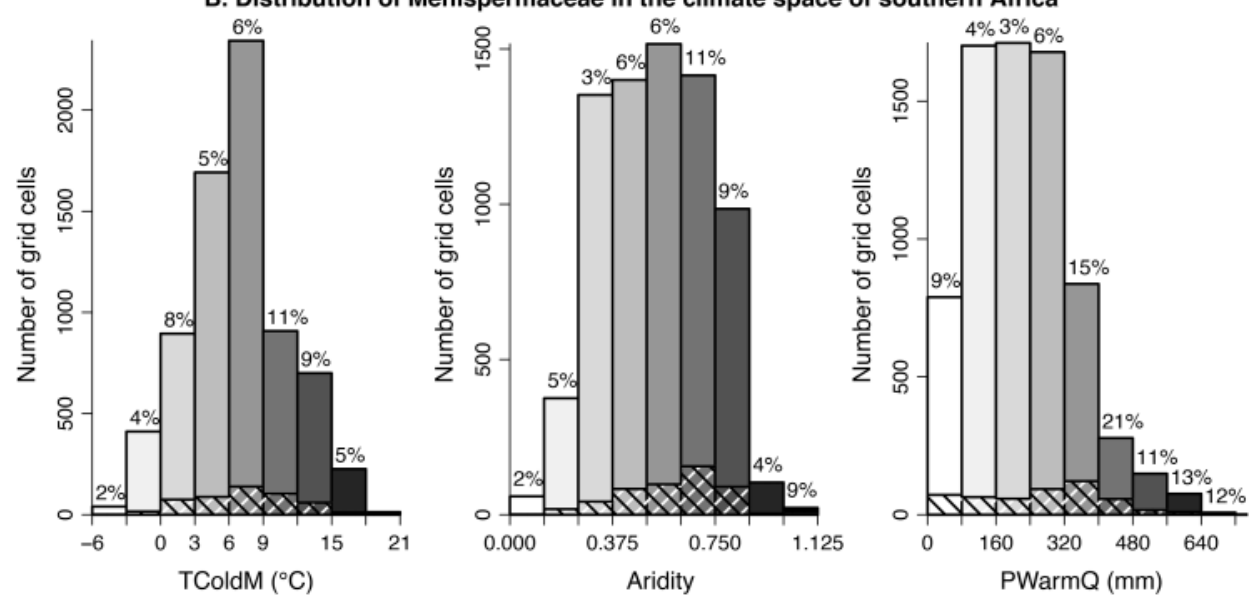

C. pdfs of Menispermaceae in the climate space of southern Africa
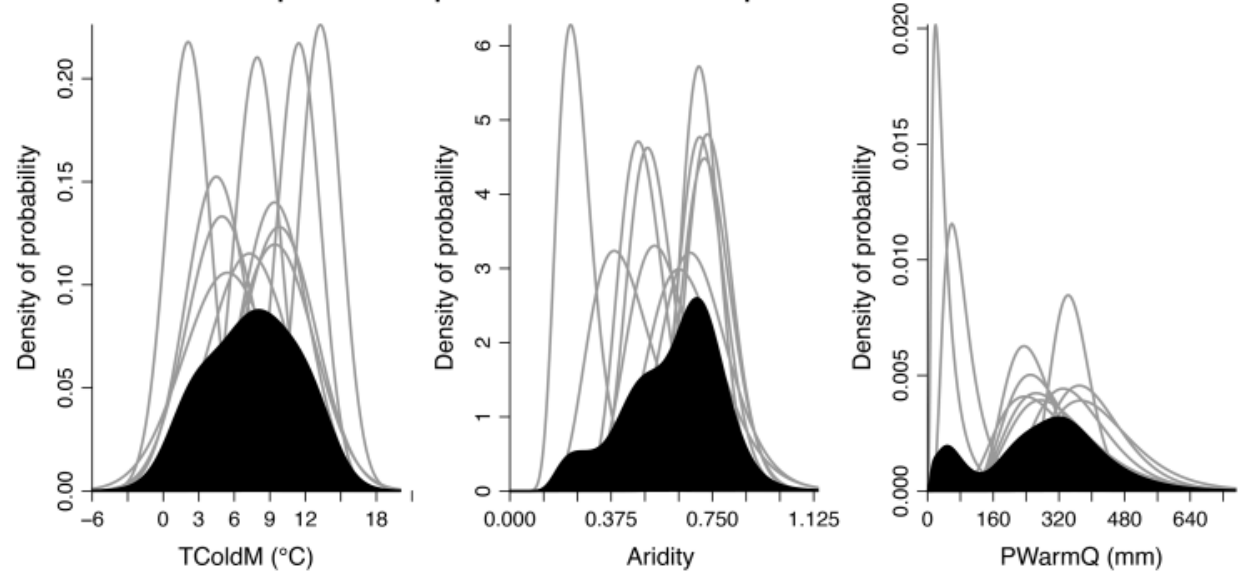

Figure 5. (A) Distribution of Menispermaceae across the study area (661 occurrences, 494 unique occurrences). (B) Histogram that represents the proportion of the climate space (grey scalee histogram) that is occupied (hatched histogram) by at least one Menispermaceae species. 5-10\% of each class are occupied by at least one species. (C) pdfs fitted on each species (grey) highlighting the diversity of the individual responses and their broad combined pdf (black). 

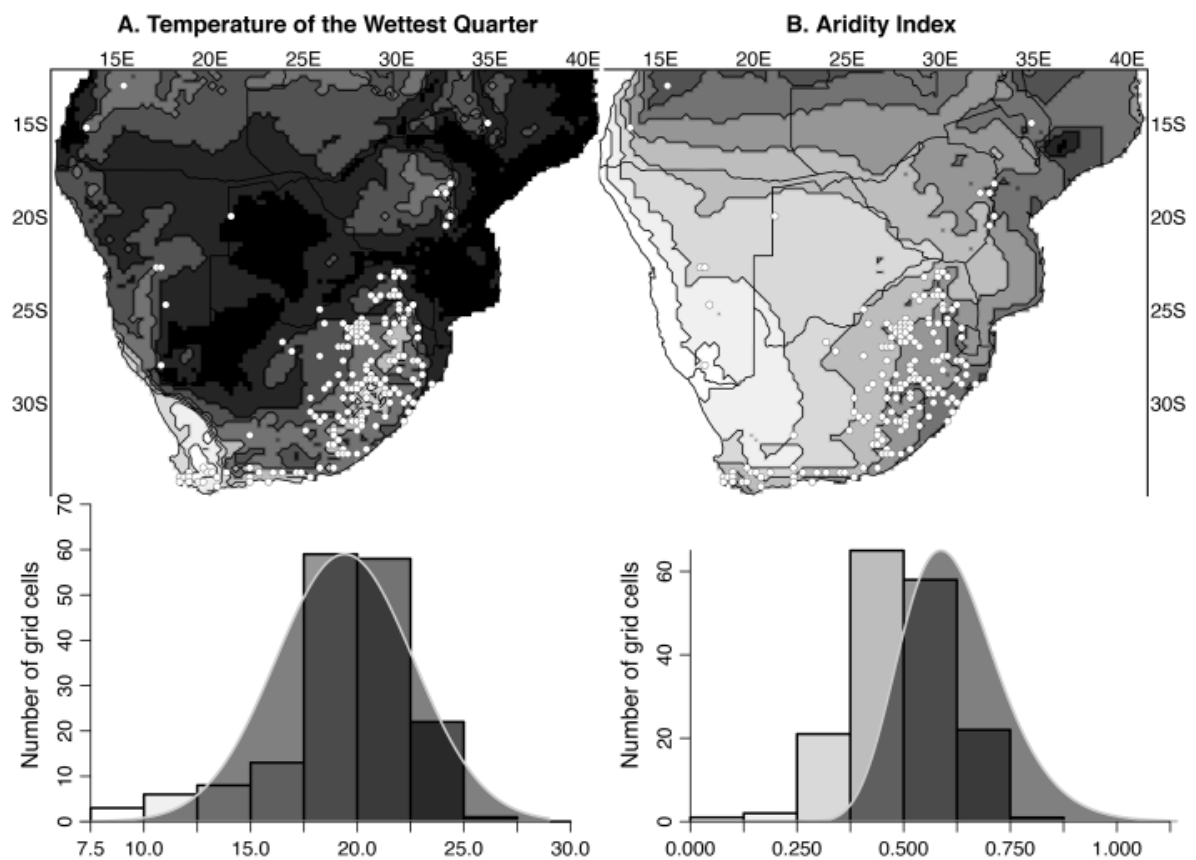

$\left({ }^{\circ} \mathrm{C}\right)$

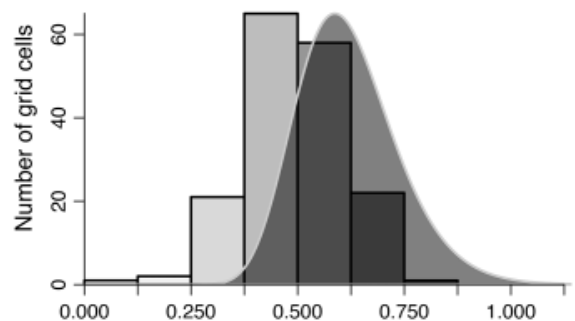

C. Precipitation of the Warmest Quarter

D. Minimum temperature of the coldest month
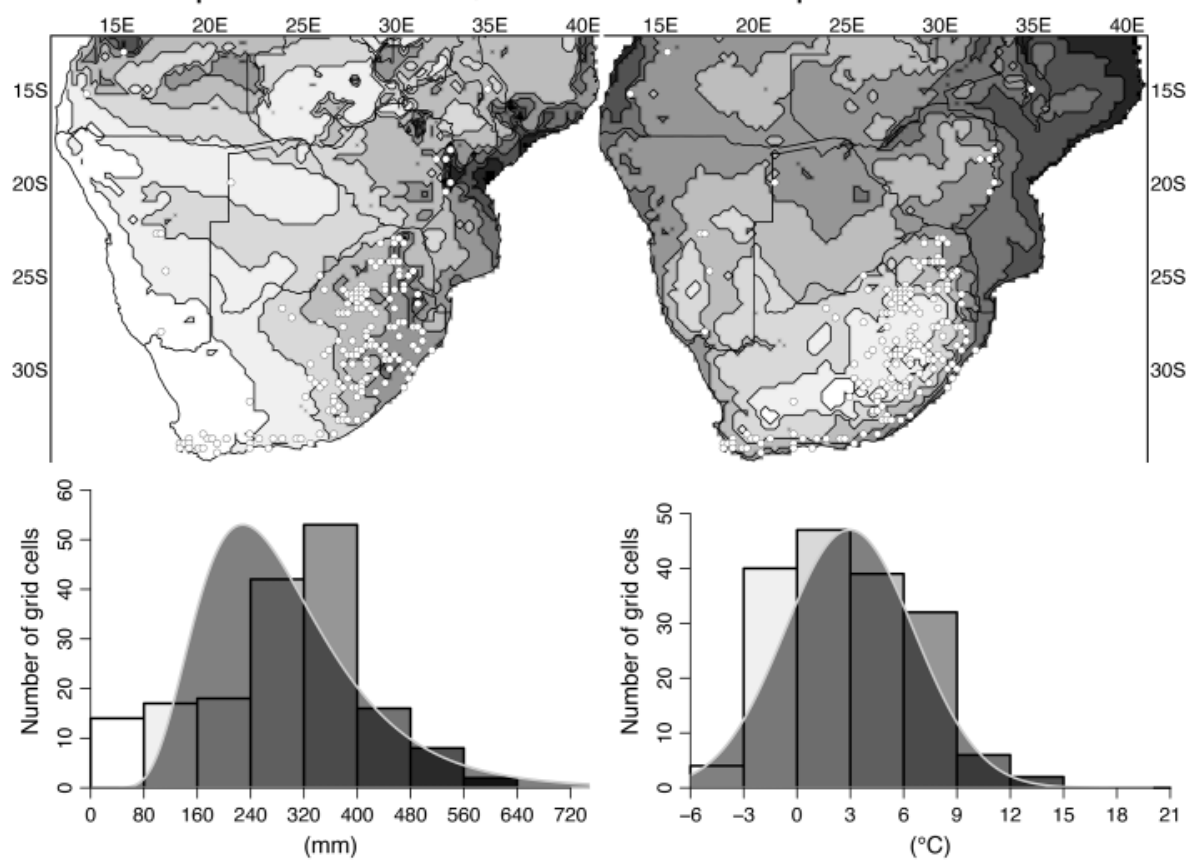

Figure 6. Distribution of Artemisia (white dots; 172 unique occurrences) plotted against four different climate gradients and summarised as histograms and respective pdf. The combination of TWetQ and Aridity (top row) allows inferring that Artemisia grows in cool and mesic conditions in southern Africa. 
Finally, it should also be noted that any assessments of sensitivity from this study relate to the southern African context and the geographical and climatic spaces here defined (Figures 1 and 2), with a clear focus on the southern half of the study area due to distribution of plant occurrence data (Figure 1A). These results are also mainly valid at the spatial scale of the atlas and they could be superseded by local constraints (e.g. edaphic conditions). As such, extrapolating these results beyond this geographical range and spatial resolution should only be done carefully.

\subsubsection{Identification of climatically 'uninformative' taxa}

Some pollen types are not useful for quantitative climatic reconstructions because of the diversity of species producing pollen of indistinguishable morphologies. Best illustrated by Poaceae (1266 species grouped into 242 genera in our southern African botanical database; Figure 4), the diversity issue highlights one limitation of many statistical tools as there is no simple, unique link between the presence records and the associated climate values. Presumably present (almost) everywhere in southern Africa (Poaceae species have been observed in about $60 \%$ of all Aridity classes, see Figure 4), only their spatially-varying relative abundance in the modern environment (unavailable data) may contain reliable climatic information. In fact, when the number of species becomes too large, and the niches too diverse, the pdfs of such taxa are not flat - as with the pdfs of uninformative taxa - but rather exhibit a peak that reflects the distribution of the whole climate space rather than specific sensitivities (see Poaceae on pp. 234-235 of the atlas (Chevalier et al. 2021b), but also other taxa, such as Scrophulariaceae-type [pp. 272-273], Asteraceae [pp. 60-61] or Fabaceae [pp. 124-125]).

The degree of scattering of the different species pdfs along the climate gradient is another characteristic that may mask any potential climatic signal from being conveyed. As an example, Menispermaceae - composed of 30 species in southern Africa, but with only 10 having at least 20 grid cells in their distribution - can be found in a large range of distinct environments, as each species occupies a unique geographical and climatic niche (Figure 5). This means that Menispermaceae pollen cannot easily be interpreted in terms of climate (at least not for the five climate variables selected here) and, as such, cannot be directly used to reconstruct past climates without additional assumptions to deconvolve the different species signals. Such situations can be identified by observing the geographical distribution of the taxon (Figure 5A), but also by looking at the distribution of the taxon in the climate space (Figure 5B) and the shape of the pdfs, which are generally multimodal and/or associated with a high variance despite a limited number of composing species (Figure 5C).

\subsubsection{Identification of climate sensitivities}

Geographical distributions, species diversity, and the shapes of the pdfs can be reliable criteria for identifying taxa from which climatic information cannot be extracted from their distributions. However, identifying the most important climate sensitivities of the 'informative' taxa (i.e. the taxa from which specific climate sensitivities can be inferred from their distribution) is less direct, especially since plants are often sensitive to a range of climatic parameters. In practice, the distribution, availability and accessibility of different climates within any definite climate space generally reduce that multifactorial sensitivity aspect to one or two specific parameters that most strongly limit the plants' distributions.

Using the monospecific Artemisia pollen type (Artemisia afra) as a case study to illustrate the process of identification of climate sensitivities, the criteria aforementioned - especially the shapes of the pdfs - are unreliable indicators of climate sensitivities (Figure 6). By construction, 
the shape of monospecific pollen types is constrained and will appear smooth. In such situations, looking at the distribution of Artemisia in the southern African climate space, and more specifically where it grows and where it does not grow, provides additional valuable information to discriminate between constraining and non-constraining variables. Real absence data are not available here, but it has been suggested that when the modern presence record dataset is sufficiently extensive, pseudo-absence records can be inferred (Elith and Leathwick 2009; Elith et al. 2006; e.g. Birks et al. 2010). Superimposing plant distributions on climate layers thus sheds light on whether a variable is important or not. Maps in Figure 6 show that most records of Artemisia (c. $70 \%$ of the distribution) occur between TWetQ values of 17.5 to $25^{\circ} \mathrm{C}$. Artemisia is rarely found in warmer or colder areas, and, therefore, TWetQ seems to apply a relatively strong constraint on the plant's distribution. Similarly, the distribution of Aridity Index values seems to also constrain the distribution of Artemisia which is mainly found at values between 0.25-0.75. In contrast, Artemisia is observed across the entire PWarmQ (23 to $616 \mathrm{~mm}$ ) and PColdQ ( 1 to $340 \mathrm{~mm}$ ) precipitation gradients. The false impression that Artemisia needs elevated summer rainfall is caused by the orographic effect of the higher altitude regions of eastern South Africa that locally correlates cool temperatures with high summer precipitation. Combined these maps suggest that Artemisia is more directly limited by a combination of average-to-cool temperatures of the growing season and mesic conditions rather than by precipitation amount specifically, at least in the southern African context.

The same approach of superposing the distributions with climate gradients can be used to highlight some specific sensitivities. For example, the distribution of Podocarpus is strongly correlated with high humidity values (Chevalier et al. 2021b, pp. 236-237), while Zygophyllum's distribution is concentrated on the other side of the aridity gradient in the most arid grid cells [pp. 312-313]. Brachystegia [pp. 66-67] lives in the hottest and most humid sections of our climate space, while Burkea [pp. 68-69] has a similar thermal niche but a preference for more mesic climates. These assessments are consistent with previous interpretations, but the data presented here clarifies and validates these interpretations, and perhaps more importantly, contributes to a common understanding of a broader range of plant-climate relationships and environmental sensitivities in southern Africa.

\subsubsection{Relative comparisons of the climate preferences}

The pdfs allow for an individual assessment of each pollen type for each variable. However, it can also be useful to assess relative sensitivities (Does taxon X prefer colder temperatures than taxon Y?) to better understand vegetation dynamics from a pollen diagram. To do so, the atlas also contains comparative figures of the variable-specific pdfs and also an analysis of their climate preferences by Principal Component Analysis (PCA) run on the five climate optima (Chevalier et al. 2021b, pp. 315-338). Here, we present the same analysis performed on the 40 most common pollen types in southern African records (Figures 7 and 8).

The first two axes represent $>80 \%$ of the total variance and separate plant taxa according to different groups. The bottom left corner is occupied with taxa with preferences for low temperatures during the growing season, the top left quadrant shows a gradient of taxa that preferentially live in arid to semi-arid conditions, while the right half consists of taxa that prefer summer-rainfall conditions. The position of Artemisia near the centre of the PCA biplot supports our interpretation that this taxon is preferentially associated with average climate conditions in southern Africa. However, it should be noted that this PCA approach is only one element to consider and is not an absolute descriptor of relative tolerances. This PCA analysis is only based on climate optima and not the tolerances and of secondary optima of the pdfs. As shown in Figure 8 , Geraniaceae has an arid climate optimum (c. 0.25$)$, but its tolerance is large (c. $0.15-0.8)$, as distinct Geraniaceae species can grow across the entire aridity gradient of the region (Chevalier 


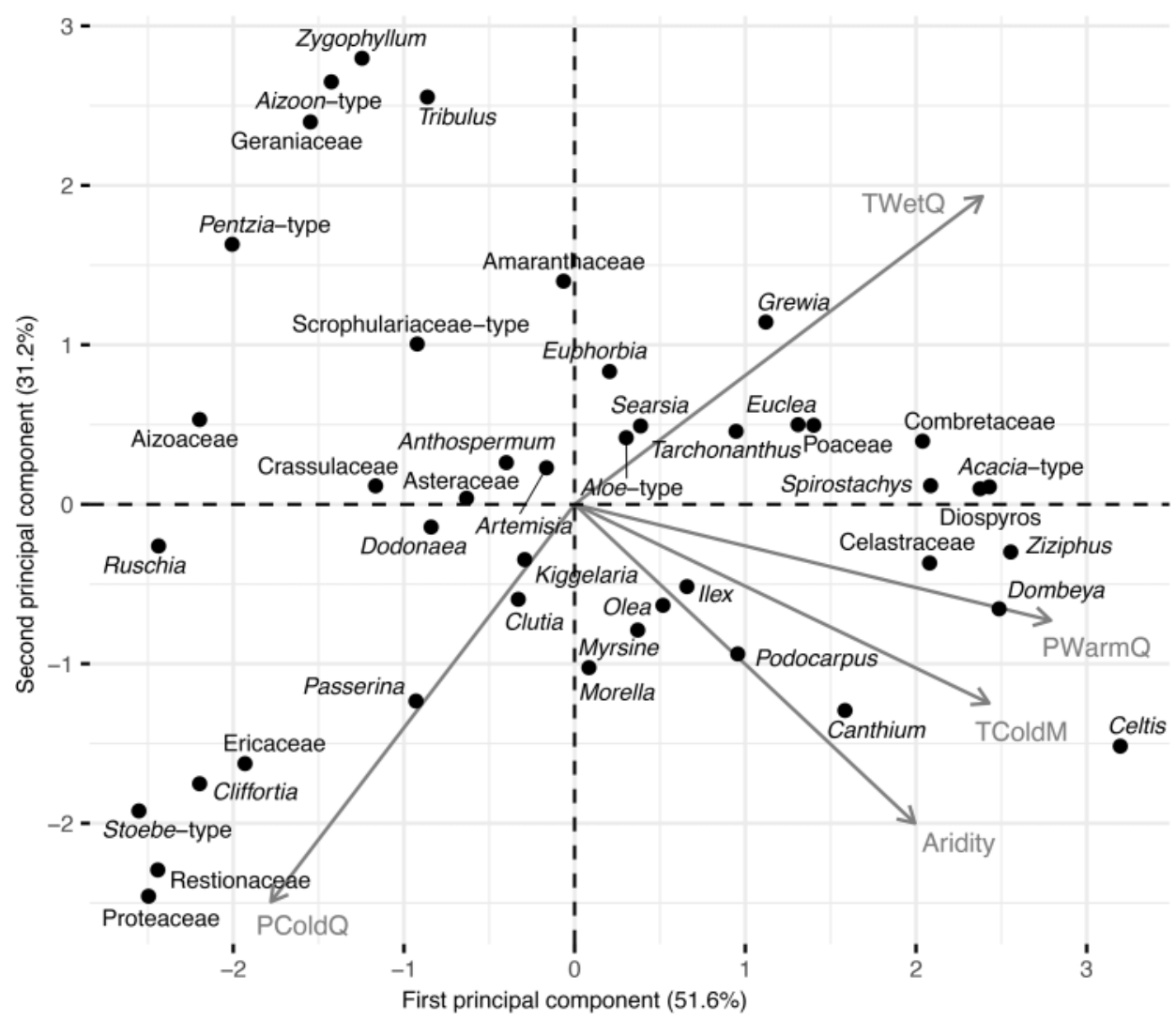

Figure 7. Scatterplot of the two first principal components of the PCA run with the five climate optima of the 40 most frequent pollen types in southern African records.

et al. 2021b, pp. 136-137). Scrophulariaceae-type (Chevalier et al. 2021b, pp. 272-273) as a similarly broad tolerance to the aridity gradient but with an optimum towards sub-humid values.

\subsection{DISCUSSION AND CONCLUSIONS}

The diagnostic tools presented in this paper are derived from the statistical analyses of modern plant distributions and provide a robust framework from which consistent interpretations of pollen data can be obtained. The three case studies were chosen to represent specific issues associated with the identification of climate sensitivities (high taxonomic diversity with Poaceae, scattering in the climate space with Menispermaceae and locally-correlated factors with Artemisia). While the first two are easily identified, confounding factors may be more difficult, and can lead to erroneous interpretations, especially when transposed back in time (Juggins 2013; Telford and Birks 2011). Confounding factors can only be detected when all the climatic and environmental aspects that matter to the plant life cycle are being considered. However, it should be kept in mind that since we only considered five climate variables, the full range of possibilities may not be always realised, and climatic factors important to certain taxa may not have been included in the atlas. 


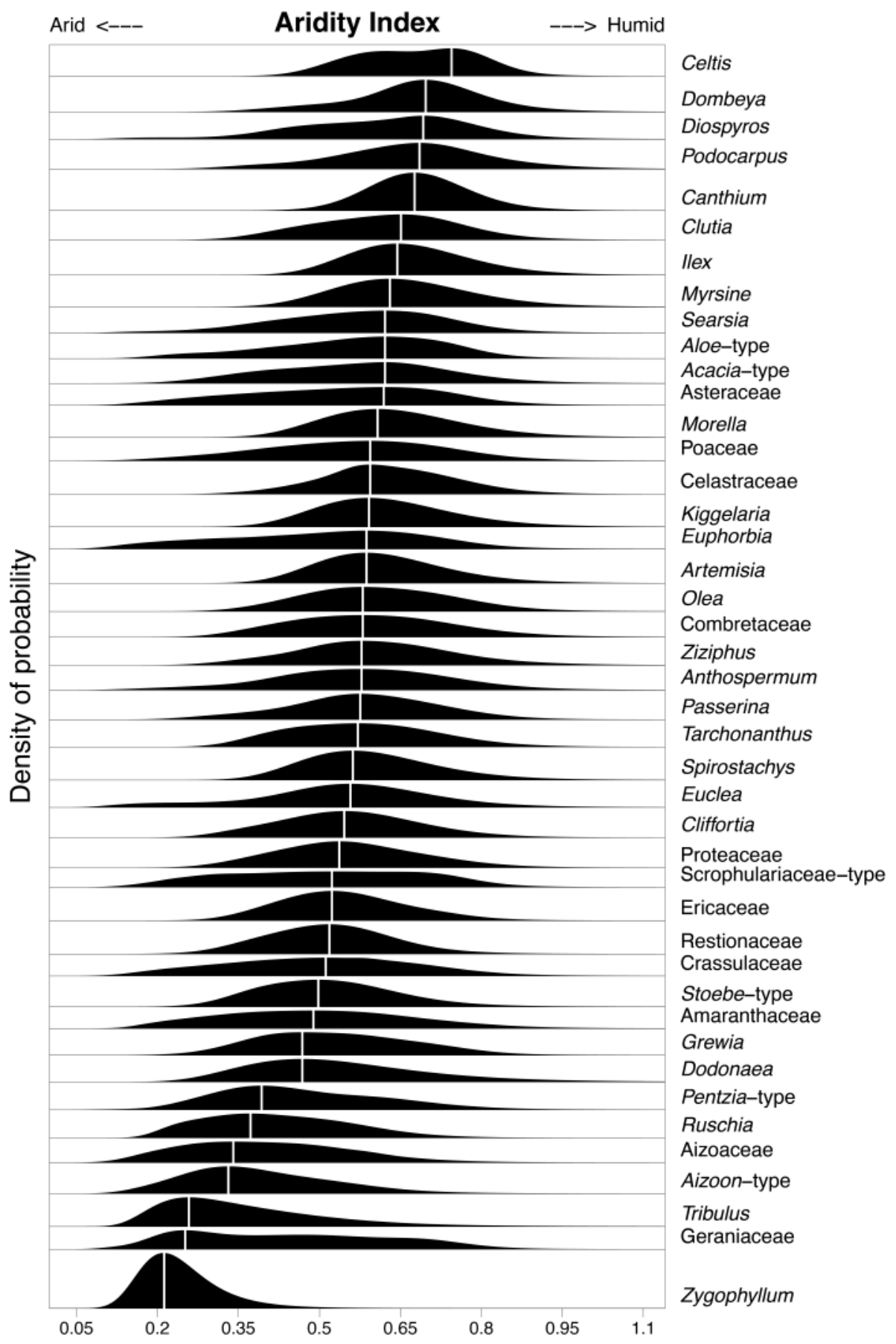

Figure 8. Aridity Index pdfs of the 40 most frequent taxa in southern African pollen records. Taxa are sorted from bottom (drier) to top (more humid) according to their climate optimum, not their tolerance. 
Further, plant taxon distributions do not necessarily equal their pollen distributions precisely, as indicated by Hamilton (1972) for East Africa. Where available, knowledge of pollen distribution and preservation mechanisms could be used to adjust pollen-interpreted reconstructions. It is also important to remember that non-climatic factors such as fire or edaphic conditions are also important - even decisive - drivers of some plant distributions. Therefore, even if these diagnostic tools represent a valuable source of information regarding plant-climate relationships, they should always be considered in combination with ecological/botanical knowledge to ensure that essential aspects have not been ignored.

In addition, it is important to note that a climate sensitivity does not give any indication of the actual sign of the signal conveyed by the pollen (e.g. wetter or drier, warmer or colder). In fact, the sign of a signal is a relative concept that depends exclusively on the assemblage in which the taxon was observed. For instance, the relatively xeric Pentzia-type (Chevalier et al. 2021b, pp. 224-225) was on average an indicator of more humid environments in the Desert Biome at Pella, South Africa during the Holocene (Lim et al. 2016), while it was generally indicative of more arid environments in records from the more humid climates of eastern South Africa (Chevalier and Chase 2016). This relativity includes temporally-varying signatures relating to long-term changes in climate (e.g. Tarchonanthus [pp. 292-293] as a high and low precipitation indicator at Wonderkrater, South Africa (Chevalier and Chase 2015)).

Finally, while this paper is dedicated to the analysis of southern African pollen types, all the diagnostic tools presented are transferable and applicable to other regions of the World and/or different ecosystems as they are based on the crestr R package (https:/github.com/mchevalier2/ crestr) and can be generated using R scripts available at https://github.com/mchevalier2/Papers/ tree/master/2021_Chevalier_etal_Pollen_Atlas_SA. This technique will help to formalise and standardise pollen-climate interpretations and facilitate and refine interpretations of regional fossil pollen data.

\subsection{DATA AVAILABILITY}

The 'Atlas of southern African pollen types and their climatic affinities' is available from https:// doi.org/10.5281/zenodo.4013452.

\section{ACKNOWLEDGEMENTS}

This work was supported by the European Research Council (ERC) under the European Union's Seventh Framework Programme (FP7/2007-2013)/ERC Starting Grant 'HYRAX', grant agreement no. 258657. The authors also acknowledge the support of the South African National Botanical Institute (SANBI) in sharing their botanical data. Lloyd Rossouw, Alma Fuller and Frederick Scott for scanning and arranging negatives of the pollen reference collection of the Department of Plant Sciences University of the Free State in a database. LS was supported by the National Research foundation (South Africa) (NRF Grant no. 85903). Any opinion, finding, and conclusion or recommendation expressed in this material is that of the authors, and the NRF does not accept any liability in this regard.

\section{REFERENCES}

Birks, H.J.B., Heiri, O., Seppä, H. and Bjune, A.E., 2010, Strengths and weaknesses of quantitative climate reconstructions based on Late-Quaternary biological proxies. The Open Ecology Journal, 3, pp. 68-110, 10.2174/1874213001003020068. 
Bousman, C.B., Metcalfe, S.E., Partridge, T.C., Vogel, J.C. and Brink, J.S., 1988, Palaeoenvironmental implications of Late Pleistocene and Holocene valley fills in Blydefontein basin, Noupoort, CP, South Africa. Palaeoecology of Africa, 19, pp. 43-67.

Bray, P.J., Blockley, S.P.E., Coope, G.R., Dadswell, L.F., Elias, S.A., Lowe, J.J. and Pollard, A.M., 2006, Refining mutual climatic range (MCR) quantitative estimates of palaeotemperature using ubiquity analysis. Quaternary Science Reviews, 25, pp. 1865-1876, 10.1016/j.quascirev.2006.01.023.

Chase, B.M., Boom, A., Carr, A.S., Carré, M., Chevalier, M., Meadows, M.E., Pedro, J.B., Stager, J.C. and Reimer, P.J., 2015a, Evolving southwest African response to abrupt deglacial North Atlantic climate change events. Quaternary Science Reviews, 121, pp. 132-136, 10.1016/j.quascirev.2015.05.023.

Chase, B.M., Lim, S., Chevalier, M., Boom, A., Carr, A.S., Meadows, M.E. and Reimer, P.J., $2015 \mathrm{~b}$, Influence of tropical easterlies in the southwestern Cape of Africa during the Holocene. Quaternary Science Reviews, 107, pp. 138-148, 10.1016/j.quascirev.2014.10.011.

Chase, B.M., Chevalier, M., Boom, A. and Carr, A.S., 2017, The dynamic relationship between temperate and tropical circulation systems across South Africa since the last glacial maximum. Quaternary Science Reviews, 174, pp. 54-62, 10.1016/j.quascirev.2017.08.011.

Chevalier, M., 2018, GBIF database for CREST. https://doi.org/10.6084/m9.figshare.6743207

Chevalier, M., 2019, Enabling possibilities to quantify past climate from fossil assemblages at a global scale. Global and Planetary Change, 175, pp. 27-35, 10.1016/j.gloplacha.2019.01.016.

Chevalier, M. and Chase, B.M., 2015, Southeast African records reveal a coherent shift from high- to low-latitude forcing mechanisms along the east African margin across last glacial-interglacial transition. Quaternary Science Reviews, 125, pp. 117-130, 10.1016/j.quascirev.2015.07.009.

Chevalier, M. and Chase, B.M., 2016, Determining the drivers of long-term aridity variability: a southern African case study. Journal of Quaternary Science, 31, pp. 143-151, $10.1002 / \mathrm{jqs} .2850$.

Chevalier, M., Chase, B.M., Quick, L.J., Dupont, L.M. and Johnson, T.C., 2021a, Temperature change in subtropical southeastern Africa during the past 790,000 yr. Geology, 49, pp. 71-75, 10.1130/G47841.1.

Chevalier, M., Chase, B.M., Quick, L.J. and Scott, L., 2021b, Atlas of southern African pollen taxa (V1.1). https://doi.org/10.5281/zenodo.4013452

Chevalier, M., Cheddadi, R. and Chase, B.M., 2014, CREST (Climate REconstruction SofTware): a probability density function (PDF)-based quantitative climate reconstruction method. Climate of the Past, 10, pp. 2081-2098, 10.5194/cp-10-2081-2014.

Chevalier, M., Davis, B.A.S., Heiri, O., Seppä, H., Chase, B.M., Gajewski, K., Lacourse, T., Telford, R.J., Finsinger, W., Guiot, J., Kühl, N., Maezumi, S.Y., Tipton, J.R., Carter, V.A., Brussel, T., Phelps, L.N., Dawson, A., Zanon, M., Vallé, F., Nolan, C., Mauri, A., de Vernal, A., Izumi, K., Holmström, L., Marsicek, J., Goring, S., Sommer, P.S., Chaput, M. and Kupriyanov, D., 2020, Pollen-based climate reconstruction techniques for late Quaternary studies. Earth-Science Reviews, 210, article: 103384, 10.1016/j.earscirev.2020.103384.

Coetzee, J.A., 1955, The morphology of Acacia pollen. South African Journal of Science, 52, pp. 23-27.

Coetzee, J.A., 1967, Pollen analytical studies in East and Southern Africa. Palaeoecology of Africa and the Surrounding Islands, 3, pp. 1-146.

Cooremans, B., 1989, Pollen production in central southern Africa. Pollen et Spores, 31, pp. 61-78.

Cordova, C.E., Scott, L., Chase, B.M. and Chevalier, M., 2017, Late Pleistocene-Holocene vegetation and climate change in the Middle Kalahari, Lake Ngami, Botswana. Quaternary Science Reviews, 171, pp. 199-215, 10.1016/j.quascirev.2017.06.036. 
Elith, J. and Leathwick, J.R., 2009, Species Distribution Models: Ecological Explanation and Prediction Across Space and Time. Annual Review of Ecology, Evolution, and Systematics, 40, pp. 677-697, 10.1146/annurev.ecolsys.110308.120159.

Elith, J., Graham, C.H., Anderson, R.P., Dudík, M., Ferrier, S., Guisan, A., Hijmans, R.J., Huettmann, F., Leathwick, J.R., Lehmann, A., Li, J., Lohmann, L.G., Loiselle, B.A., Manion, G., Moritz, C., Nakamura, M., Nakazawa, Y., McC. M. Overton, J., Townsend Peterson, A., Phillips, S.J., Richardson, K., Scachetti-Pereira, R., Schapire, R.E., Soberón, J., Williams, S., Wisz, M.S. and Zimmermann, N.E., 2006, Novel methods improve prediction of species' distributions from occurrence data. Ecography, 29, pp. 129-151, 10.1111/j.2006.0906-7590. 04596.x.

Fick, S.E. and Hijmans, R.J., 2017, WorldClim 2: new 1-km spatial resolution climate surfaces for global land areas. International Journal of Climatology, 37, pp. 4302-4315, 10.1002/joc.5086.

Finch, J.M. and Hill, T.R., 2008, A late Quaternary pollen sequence from Mfabeni Peatland, South Africa: Reconstructing forest history in Maputaland. Quaternary Research, 70, pp. 442-450.

GBIF: Global Biodiversity Information Facility, 2018.

GBIF.org, 2020a, Anthocerotopsida occurrence data downloaded on September 24th, 2020. https://doi.org/10.15468/dl.t9zenf

GBIF.org, 2020b, Cycadopsidae occurrence data downloaded on September 24th, 2020. https://doi.org/10.15468/dl.sfjzxu

GBIF.org, 2020c, Liliopsida occurrence data downloaded on September 24th, 2020. https://doi.org/10.15468/dl.axv3yd

GBIF.org, 2020d, Polypodiopsida occurrence data downloaded on September 24th, 2020. https://doi.org/10.15468/dl.87tbp6

GBIF.org, 2020e, Gnetopsidae occurrence data downloaded on September 24th, 2020. https://doi.org/10.15468/dl.h2kjnc

GBIF.org, 2020f, Gingkoopsidae occurrence data downloaded on September 24th, 2020. https://doi.org/10.15468/dl.da9wz8

GBIF.org, 2020g, Pinopsidae occurrence data downloaded on September 24th, 2020. https://doi.org/10.15468/dl.x2r7pa

GBIF.org, 2020h, Magnoliopsida occurrence data downloaded on September 24th, 2020. https://doi.org/10.15468/dl.ra49dt

GBIF.org, 2020i, Lycopodiopsida occurrence data downloaded on September 24th, 2020. https://doi.org/10.15468/dl.ydhyhz

Guisan, A. and Thuiller, W., 2005, Predicting species distribution: offering more than simple habitat models. Ecology Letters, 8, pp. 993-1009, 10.1111/j.1461-0248.2005. 00792.x.

Guisan, A. and Zimmermann, N.E., 2000, Predictive habitat distribution models in ecology. Ecological Modelling, 135, pp. 147-186, 10.1016/S0304-3800(00)00354-9.

Hamilton, A.C., 1972, The interpretation of pollen diagrams from highland Uganda. Palaeoecology of Africa, 7, pp. 45-149.

Imbrie, J. and Kipp, N.G., 1971, A new micropaleontological method for quantitative paleoclimatology: application to a Late Pleistocene Caribbean core. The Late Cenozoic Glacial Ages., 3, pp. 71-181.

Juggins, S., 2013, Quantitative reconstructions in palaeolimnology: New paradigm or sick science? Quaternary Science Reviews, 64, pp. 20-32, 10.1016/j.quascirev.2012. 12.014 .

Juggins, S., Simpson, G.L. and Telford, R.J., 2015, Taxon selection using statistical learning techniques to improve transfer function prediction. The Holocene, 25, pp. 130-136, $10.1177 / 0959683614556388$.

Kearney, M., 2006, Habitat, environment and niche: what are we modelling?. OIKOS, 115, pp. 186-191, 10.1111/j.2006.0030-1299.14908.x. 
Kühl, N., Gebhardt, C., Litt, T. and Hense, A., 2002, Probability Density Functions as BotanicalClimatological Transfer Functions for Climate Reconstruction. Quaternary Research, 58, pp. 381-392, 10.1006/qres.2002.2380.

Lim, S., Chase, B.M., Chevalier, M. and Reimer, P.J., 2016, 50,000 years of climate in the Namib Desert, Pella, South Africa. Palaeogeography, Palaeoclimatology, Palaeoecology, 451, pp. 197-209, 10.1016/j.palaeo.2016.03.001.

Myers, N., Mittermeier, R.A., Mittermeier, C.G., da Fonseca, G.A.B. and Kent, J., 2000, Biodiversity hotspots for conservation priorities. Nature, 403, pp. 853-858, 10.1038/35002501.

Neumann, F.H., Scott, L., Bousman, C.B. and van As, L., 2010, A Holocene sequence of vegetation change at Lake Eteza, coastal KwaZulu-Natal, South Africa. Review of Palaeobotany and Palynology, 162, pp. 39-53, 10.1016/j.revpalbo.2010.05.001.

Neumann, F.H., Scott, L. and Bamford, M.K., 2011, Climate change and human disturbance of Fynbos vegetation during the late Holocene at Princess Vlei, Western Cape, South Africa. The Holocene, 21, pp. 1137-1149, 10.1177/0959683611400461.

Neumann, F.H., Botha, G.A. and Scott, L., 2014, 18,000 years of grassland evolution in the summer rainfall region of South Africa: evidence from Mahwaqa Mountain, KwaZulu-Natal. Vegetation History and Archaeobotany, 23, pp. 665-681, 10.1007/s00334-014-0445-3.

Overpeck, J.T., 1985, A pollen study of a late Quaternary peat bog, south-central Adirondack Mountains, New York. Geological Society of America Bulletin, 96, pp. 145-154, 10.1130/00167606(1985)96\#<145:APSOAL\#>2.0.CO;2.

Quick, L.J., Meadows, M.E., Bateman, M.D., Kirsten, K.L., Mäusbacher, R., Haberzettl, T. and Chase, B.M., 2016, Vegetation and climate dynamics during the last glacial period in the fynbos-afrotemperate forest ecotone, southern Cape, South Africa. Quaternary International, 404, pp. 136-149, 10.1016/j.quaint.2015.08.027.

Quick, L.J., Chase, B.M., Wündsch, M., Kirsten, K.L., Chevalier, M., Mäusbacher, R., Meadows, M.E. and Haberzettl, T., 2018, A high-resolution record of Holocene climate and vegetation dynamics from the southern Cape coast of South Africa: pollen and microcharcoal evidence from Eilandvlei. Journal of Quaternary Science, 33, pp. 487-500, 10.1002/jqs.3028.

Rutherford, M.C., Mucina, L. and Powrie, L., 2012, The South African National Vegetation Database: History, development, applications, problems and future. South African Journal of Science, 108, pp. 1-8, 10.4102/sajs.v108i1/2.629.

Scott, L., 1982, Late Quaternary fossil pollen grains from the Transvaal, South Africa. Review of Palaeobotany and Palynology, 36, pp. 241-278, 10.1016/0034-6667(82)90022-7.

Scott, L., 1989, Climatic conditions in Southern Africa since the last glacial maximum, inferred from pollen analysis. Palaeogeography, Palaeoclimatology, Palaeoecology, 70, pp. 345-353, 10.1016/0031-0182(89)90112-0.

Scott, L., 1999, Vegetation history and climate in the Savanna biome South Africa since 190,000 ka: a comparison of pollen data from the Tswaing Crater (the Pretoria Saltpan) and Wonderkrater. Quaternary International, 58, pp. 215-223, 10.1016/S1040-6182(98)00062-7.

Scott, L. and Nyakale, M., 2002, Pollen indications of Holocene palaeoenvironments at Florisbad spring in the central Free State, South Africa. The Holocene, 12, pp. 497-503, $10.1191 / 0959683602 \mathrm{hl} 563 \mathrm{rr}$.

Scott, L. and Woodborne, S., 2007, Vegetation history inferred from pollen in Late Quaternary faecal deposits (hyraceum) in the Cape winter-rain region and its bearing on past climates in South Africa. Quaternary Science Reviews, 26, pp. 941-953, 10.1016/j.quascirev.2006.12.012.

Scott, L., Neumann, F.H., Brook, G.A., Bousman, C.B., Norström, E. and Metwally, A.A.S.A.H., 2012, Terrestrial fossil-pollen evidence of climate change during the last 26 thousand years in Southern Africa. Quaternary Science Reviews, 32, pp. 100-118, 10.1016/j.quascirev.2011.11.010. 
Telford, R.J. and Birks, H.J.B., 2011, A novel method for assessing the statistical significance of quantitative reconstructions inferred from biotic assemblages. Quaternary Science Reviews, 30, pp. 1272-1278, 10.1016/j.quascirev.2011.03.002.

ter Braak, C.J.F. and Looman, C.W.N., 1986, Weighted averaging, logistic regression and the Gaussian response model. Vegetatio, 65, pp. 3-11, 10.1007/BF00032121.

ter Braak, C.J.F. and Juggins, S., 1993, Weighted averaging partial least squares regression (WA-PLS): an improved method for reconstructing environmental variables from species assemblages. Hydrobiologia, 269-270, pp. 485-502, 10.1007/BF00028046.

Trabucco, A. and Zomer, R.J., 2019, Global Aridity Index and Potential Evapotranspiration (ET0) Climate Database v2.

Trabucco, A., Zomer, R.J., Bossio, D.A., van Straaten, O. and Verchot, L. V., 2008, Climate change mitigation through afforestation/reforestation: A global analysis of hydrologic impacts with four case studies. Agriculture, Ecosystems \& Environment, 126, pp. 81-97, 10.1016/j.agee.2008.01.015.

Truc, L., Chevalier, M., Favier, C., Cheddadi, R., Meadows, M.E., Scott, L., Carr, A.S., Smith, G.F. and Chase, B.M., 2013, Quantification of climate change for the last 20,000 years from Wonderkrater, South Africa: implications for the long-term dynamics of the Intertropical Convergence Zone. Palaeogeography, Palaeoclimatology, Palaeoecology, 386, pp. 575-587, 10.1016/j.palaeo.2013.06.024.

Turner, M.G., Wei, D., Prentice, I.C. and Harrison, S.P., 2020, The impact of methodological decisions on climate reconstructions using WA-PLS. Quaternary Research, pp. 1-16, 10.1017/qua.2020.44.

Valsecchi, V., Chase, B.M., Slingsby, J.A., Carr, A.S., Quick, L.J., Meadows, M.E., Cheddadi, R. and Reimer, P.J., 2013, A high resolution 15,600-year pollen and microcharcoal record from the Cederberg Mountains, South Africa. Palaeogeography, Palaeoclimatology, Palaeoecology, 387, pp. 6-16, 10.1016/j.palaeo.2013.07.009.

van Zinderen Bakker, E.M., 1953, South African Pollen Grains and Spores, Volume I, (Cape Town: AA Balkema).

van Zinderen Bakker, E.M., 1956, South African Pollen Grains and Spores, Volume II, (Cape Town: AA Balkema).

van Zinderen Bakker, E.M., 1957, A pollen analytical investigation of the Florisbad deposits (South Africa), in: Proceedings of the Third Pan African Congress on Prehistory. Livingstone, Chatto and Windus, London. pp. 56-67.

van Zinderen Bakker, E.M., 1982, Pollen analytical studies of the Wonderwerk Cave, South Africa. Pollen et Spores, 24, pp. 235-250.

van Zinderen Bakker, E.M. and Coetzee, J.A., 1959, South African Pollen Grains and Spores, Volume III, (Cape Town: AA Balkema).

van Zinderen Bakker, E.M. and Coetzee, J.A., 1988, A review of late Quaternary pollen studies in east, central and southern Africa. Review of Palaeobotany and Palynology, 55, pp. 155-174, 10.1016/0034-6667(88)90083-8.

van Zinderen Bakker, E.M., Welman, M. and Kuhn, L., 1970, South African Pollen Grains and Spores, Volume IV, (Cape Town: AA Balkema). 


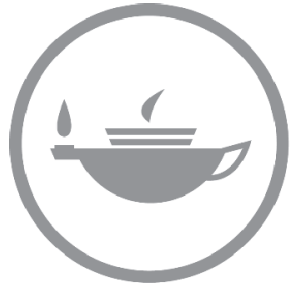

Taylor \& Francis Taylor \& Francis Group http://taylorandfrancis.com 